\title{
Correlation of electrocardiographic conduction abnormalities with myocardial fibrosis and scar in late enhancement
}

\author{
Olaf C Grebe ${ }^{1 *}$, Christa Voemel ${ }^{2}$, Bernward K Kurtz ${ }^{2}$, Ernst G Vester ${ }^{1}$ \\ From 18th Annual SCMR Scientific Sessions \\ Nice, France. 4-7 February 2015
}

\section{Background}

Late Gadolinium enhancement represents a widely employed method for detecting myocardial scarring e.g. after myocardial infarction or for myocardial Inflammation. A frequent finding is slight basal septal enhancement as well as intramyocardial enhancement, mostly referred as myocardial fibrosis. Less is known about the impact on myocardial conduction and a possible correlation to ECG findings such as atrioventricular node conduction delay and bundle branch blockations.

\section{Methods}

For 81 consecutive patients (mean age 63,5yrs, range 20$84 \mathrm{yrs}, 17$ female) referred for magnetic resonance cardiac (MRI) including a late gadolinium enhancement study scans were anonymized and correlated to an ECG performed within one week before or after the MRI. A $1.5 \mathrm{~T}$ Siemens Sonata with TIM upgrade was used. Scanning protocol comprised short- and long axis cine mode and a perfusion study with Gd-DOTA and/or T1 and T2 TSE as well as $2 \mathrm{~d}$ and $3 \mathrm{~d}$ IR short axis sequences for late enhancement. The latter was analysed visually for the study by two experienced operators and subdived as (1) normal, (2) intramyocardial fibrosis, (3) subendocardial or transmural ischemic scar and (4) bright acute inflammation or postmyocardial subepicardial enhancement pattern. The ECGs had been reevaluated by an experienced cardiologist.

\section{Results}

The baseline data between the 4 groups was similar (data given as mean values and range):

${ }^{1}$ Cardiology, EVK - Evangelist Hospital Duesseldorf, Duesseldorf, Germany Full list of author information is available at the end of the article group 1 (normal): 30 patients (37\%), LVEF 62\% (17-79\%), EDVI $73 \mathrm{ml}(40-222 \mathrm{ml})$, ventricular septum thickness (IVS) $11 \mathrm{~mm}$, age $57 \mathrm{yrs}$;

group 2 (fibrosis): 30 patients (37\%), LVEF 58\% (20-76\%), EDVI 72ml (45-142ml), IVS 13mm, age 68yrs;

group 3 (ischemic scar): 15 patients (19\%), LVEF $51 \%$ (30-76\%), EDVI 82ml (36-152ml), IVS 11mm, age 69yrs; group 4 (myocarditis): 6 patients (7\%), LVEF 55\% (42-71\%), EDVI $82 \mathrm{ml}(57-122 \mathrm{ml})$, IVS $10 \mathrm{~mm}$, age $44 \mathrm{yrs}$.

Atrial fibrillation was present in $10 \%, 20 \%, 27 \%$, and $0 \%$ respectively.

ECG findings are presented in Table 1. Group 2-3 differed significantly from each other $(\mathrm{p}<0.016)$ as well as the fibrosis vs. the normal group $\mathrm{p}<0.01$ ).

\section{Conclusions}

Abnormal ECG findings such as AV conduction delay and bundle branch blockation are significantly correlated to myocardial scarring or fibrosis in late enhancment studies.

\section{Funding}

None.

Table 1 ECG findings

\begin{tabular}{ccccccc}
\hline & normal ECG & LBBB & RBBB & HB & IVCD & AVB \\
\hline normal & $83 \%$ & $0 \%$ & $17 \%$ & $10 \%$ & $0 \%$ & $7 \%$ \\
\hline fibrosis & $47 \%$ & $10 \%$ & $10 \%$ & $13 \%$ & $27 \%$ & $20 \%$ \\
\hline ischemic scar & $47 \%$ & $20 \%$ & $7 \%$ & $0 \%$ & $27 \%$ & $20 \%$ \\
\hline myocarditis & $33 \%$ & $0 \%$ & $50 \%$ & $17 \%$ & $0 \%$ & $0 \%$ \\
\hline
\end{tabular}

LBBB/RBBB: left/right bundle branch blockation; HB: left hemi blockation; IVCD intraventricular conduction delay, AVB: atrioventricular node block (all grade I)
C Biomed Central

(c) 2015 Grebe et al; licensee BioMed Central Ltd. This is an Open Access article distributed under the terms of the Creative Commons Attribution License (http://creativecommons.org/licenses/by/4.0), which permits unrestricted use, distribution, and reproduction in any medium, provided the original work is properly cited. The Creative Commons Public Domain Dedication waiver (http:// creativecommons.org/publicdomain/zero/1.0/) applies to the data made available in this article, unless otherwise stated. 


\section{Authors' details}

${ }^{1}$ Cardiology, EVK - Evangelist Hospital Duesseldorf, Duesseldorf, Germany.

${ }^{2}$ Radiology, EVK - Evangelist Hospital Duesseldorf, Duesseldorf, Germany.

Published: 3 February 2015

\section{doi:10.1186/1532-429X-17-S1-P189}

Cite this article as: Grebe et al:: Correlation of electrocardiographic conduction abnormalities with myocardial fibrosis and scar in late enhancement. Journal of Cardiovascular Magnetic Resonance 2015 17(Suppl 1):P189.

Submit your next manuscript to BioMed Central and take full advantage of:

- Convenient online submission

- Thorough peer review

- No space constraints or color figure charges

- Immediate publication on acceptance

- Inclusion in PubMed, CAS, Scopus and Google Scholar

- Research which is freely available for redistribution

Submit your manuscript at www.biomedcentral.com/submit 